\title{
Cryopreservation of Bovine Somatic Cell Nuclear-Transferred Blastocysts: Effect of Developmental Stage
}

\author{
Dasari AMARNATH ${ }^{1)}$, Yoko KATO ${ }^{1)}$ and Yukio TSUNODA ${ }^{1)}$ \\ 1) Laboratory of Animal Reproduction, College of Agriculture, Kinki University, Nara 631-8505, \\ Japan
}

\begin{abstract}
The effect of developmental stage on the survival of bovine somatic cell nuclear-transferred blastocysts after freezing and thawing was evaluated. We also investigated how freezing affects nuclear-transferred (NT) embryos and in vitro fertilized (IVF) bovine embryos. Advanced-stage bovine NT blastocysts survived freezing better than early-stage NT blastocysts (86 vs $14 \%$ ). The trend was similar with IVF embryos ( 87 vs $30 \%$ ). At the stages tested, there was no significant difference in the survivability of NT and IVF embryos from advanced ( $86 \mathrm{vs} 87 \%$ ) or early-stage blastocysts (14 vs $30 \%$ ). The average survival rate did not differ between NT and IVF bovine embryos (50 vs $51 \%$ ). The higher survival rate of advanced-stage blastocysts compared to early-stage blastocysts in NT and IVF bovine embryos might be due to their higher cell number. In NT (128 \pm 25 vs $53 \pm 20)$ and IVF (128 \pm 29 vs $75 \pm 22$ ) groups, advanced-stage blastocysts contained a significantly higher total cell number than early-stage blastocysts. There was no difference in total cell number between advanced-stage NT and IVF blastocysts (128 \pm 25 vs $128 \pm 29$ ), however, early-stage NT and IVF blastocysts ( $53 \pm 20$ vs 75 \pm 22 ) differed significantly.
\end{abstract}

Key words: Cryopreservation, Nuclear transfer, Bovine

(J. Reprod. Dev. 50: 593-598, 2004)

S ince the birth of Dolly [1], a large number of cloned animals have been produced by somatic cell nuclear transfer using a variety of somatic cells in sheep, cattle, mice, goat and pigs [2]. Current research in this area is focused on improving the overall efficiency of this technique to the levels acceptable for the practical application of nuclear transfer in biomedicine, animal husbandry, and conservation practices [3].

Cryopreservation is the prerequisite for long term-storage, continuous availability, and transport of embryos over a long distance. It is also often used as a measure to check the quality of in vitro produced embryos. Unlike in vitro fertilization (IVF), nuclear transfer (NT) usually results in a

Accepted for publication: July 13, 2004

Correspondence: Y. Tsunoda

(e-mail: tsunoda@nara.kindai.ac.jp) small number of blastocysts due to its laborintensive procedure and lower level of development. Therefore, it would be advantageous to select good quality NT embryos and safely cryopreserve them for either embryo transfer or further studies. An efficient cryopreservation method for NT-derived embryos would thereby provide an attractive means to enhance the application of NT in biomedicine and animal industry.

There are many reports on cryopreservation of bovine IVF embryos, however, the knowledge gained might not be applicable to NT-derived embryos as they differ from IVF embryos in having a broken zona pellucida, aberrant allocation of cells between the inner cell mass (ICM) and trophectoderm (TE) [4], aberrant gene expression [5], and methylation patterns [4], and poor in vivo 
development [2].

There are only two published reports on cryopreservation of bovine NT embryos; one using embryonic cells [6] and the other using somatic cells [7]. Among the numerous factors that affect cryosurvival of IVF embryos, age, stage, and quality of the embryos, as well as their interactions, are very important [8-12]. To the best of our knowledge, there have been no attempts to systematically study the influence of developmental stage of cryopreserved NT bovine blastocysts on their post-thaw in vitro survival. Therefore, in this study we attempted to identify the developmental stage best suited for cryopreservation of NT bovine blastocysts by slow freezing using ethylene glycol as the sole cryoprotectant. We also evaluated whether there is any difference between equivalent-stage NT and IVF blastocysts in their ability to survive cryopreservation.

\section{Materials and Methods}

\section{Collection of oocytes}

Immature oocytes were isolated from ovaries collected and transported to the laboratory in normal saline at 10 to $15 \mathrm{C}$ within 24 to $30 \mathrm{~h}$ from the time of slaughter. The cumulus- oocytecomplexes were matured in TCM 199 (Gibco Inc., Grand Island, NY, USA) supplemented with 10\% fetal bovine serum (FBS; Gibco Inc.,) and human menopausal gonadotropin (hMG; $0.1 \mathrm{IU} / \mathrm{mL}$, Teikokuzoki, Japan) in a $5 \% \mathrm{CO}_{2}$ incubator at $39 \mathrm{C}$ for 18 to $24 \mathrm{~h}$. Cumulus cells were removed from oocytes by repeated pipetting after brief exposure to hyaluronidase $(30 \mathrm{IU} / \mathrm{mL})$. Only oocytes that had extruded the first polar body were used as cytoplast for NT.

\section{Embryo production by nuclear transfer}

Nuclear transfer was performed as described previously [13] with a modification in the enucleation protocol [14]. Oocytes with a first polar body were treated with $0.5 \mu \mathrm{g} / \mathrm{mL}$ demecolcine (Wako, Japan) for 30 to $60 \mathrm{~min}$ to induce membrane protrusion. The protrusion containing maternal chromosomes and first polar body were pushed out through a cut made in the zona pellucida with a sharp needle. Cumulus cells were prepared as described previously and passaged 5 to 10 times, and induced to $G_{0} / G_{1}$ by contact inhibition [15]. A single cumulus cell was introduced into the perivitelline space of the enucleated oocyte, and electrically fused and simultaneously activated by two direct current $(150 \mathrm{~V} / \mathrm{mm})$ pulses for $25 \mu \mathrm{s}$ with a $0.1 \mathrm{sec}$ interval in Zimmerman's fusion medium. Fused oocytes were cultured in CR1-aa medium with $0.3 \%$ BSA (fatty acid free) containing cycloheximide $(10 \mu \mathrm{g} / \mathrm{mL})$ for $5 \mathrm{~h}$ followed by cycloheximide-free medium till day 3 (day $1=$ day of nuclear transfer). On the third day, embryos were moved into CR1-aa medium supplemented with $10 \%$ FBS and cultured till day 7 under $5 \% \mathrm{CO}_{2}, 5 \%$ $\mathrm{O}_{2}$, and $90 \% \mathrm{~N}_{2}$ at $39 \mathrm{C}$. On the seventh day of culture, the early blastocysts and late morulae were moved into Dulbecco's modified Eagle's medium supplemented with 10\% FBS and cultured till freezing on Day 8.

\section{Embryo production by in vitro fertilization}

In vitro fertilization was performed according to a previous report [7]. Oocytes (10-15) were matured for 22 to $24 \mathrm{~h}$ and then moved into $50 \mu \mathrm{L}$ of Brackett- Oliphant medium [16] after being washed twice in the same medium. Frozen semen straws were thawed in a water bath at $37 \mathrm{C}$. Spermatozoa were washed twice by centrifugation at $600 \times \mathrm{g}$ for 5 min in modified Brackett- Oliphant medium containing caffeine (5.5 M) and heparin (2.6 IU/ $\mathrm{mL})$, and the concentration was adjusted to $2 \times 10^{6}$ / $\mathrm{mL}$. A $50-\mu \mathrm{L}$ aliquot of semen suspension was added to each $50-\mu \mathrm{L}$ droplet containing oocytes and co-cultured together for $6 \mathrm{~h}$ in a $5 \% \mathrm{CO}_{2}$ incubator at $39 \mathrm{C}$. After $6 \mathrm{~h}$ of co-incubation, cumulus cells were removed by repeated pipetting and cultured for $8 \mathrm{~d}$ (day 1 =day of in vitro fertilization) as described above.

\section{Classification of blastocysts}

While IVF embryos can be clearly classified into different developmental stages, viz., early, mid or expanding, expanded, and hatched blastocysts [17], it is difficult to classify the NT blastocysts without some ambiguity due to escape of the blastocoel at an early-stage through the cut in the zona pellucida made during nuclear transfer. On the day of freezing, the NT blastocysts were classified into advanced and early-stages based on the development and extent of the escape of the blastocoel through the zona pellucida. Along similar lines, a small portion of the zona pellucida 
of IVF embryos was also cut at the 8-cell stage, and the blastocysts developed were classified into advanced and early-stage blastocysts. For both NT and zona-pellucida-cut IVF, blastocysts containing well developed blastocoel exhibiting a distinct inner cell mass with single layer of trophectoderm were considered as advanced-stage blastocysts. The blastocysts with less defined blastocoel (less than $50 \%$ of embryonic mass) without a clear distinction between inner cell mass and trophectoderm were considered as early-stage blastocysts. In addition advanced- and early-stage blastocysts usually exhibited more than $60 \%$ or less than $40 \%$ escape of blastocoel through zona pellucida, respectively.

\section{Cell numbers of blastocysts}

Total cell number, inner cell mass and trophectoderm cell numbers of advanced-and early-stage blastocysts obtained from NT and IVF on Day 8 of in vitro culture were counted using a chemically defined staining procedure [18]. Briefly, the embryos were incubated for $30 \mathrm{sec}$ in TCM 199 containing 1\% (v/v) Triton X-100 (Sigma Chemical Co., St. Louis, MO) and $100 \mu \mathrm{g} / \mathrm{mL}$ propidium iodide (Sigma Chemical Co.), and then incubated in ethanol containing bisbenzimide ( $25 \mu \mathrm{g} / \mathrm{mL}$; Sigma Chemical $\mathrm{Co}$,) at $4 \mathrm{C}$ overnight. Fixed and stained whole blastocysts were mounted in glycerol and assessed for cell number using an inverted microscope (Nikon, Tokyo, Japan) equipped with epifluorescence.

\section{Cryopreservation}

NT and IVF blastocysts on Day 8 were classified as advanced or early stage, and were frozen following the procedure described by Voelkel and $\mathrm{Hu}$ [19]. Embryos selected for freezing were placed into freezing medium (FM) at room temperature. The FM was Dulbecco's phosphate buffered saline (Gibco Inc. modified by adding $1 \mathrm{mM} \mathrm{CaCl}, 1 \mathrm{mM}$ $\mathrm{MgCl}_{2} .6 \mathrm{H}_{2} \mathrm{O}, 5.5 \mathrm{mM}$ glucose and $0.33 \mathrm{mM}$ pyruvic acid) containing $0.3 \%$ BSA and $20 \%$ FBS. Embryos were then equilibrated for 5 min each in 0.5 and 1.0 $\mathrm{M}$ ethylene glycol (Wako, Osaka, Japan), followed by $15 \mathrm{~min}$ in $1.5 \mathrm{M}$ ethylene glycol, during which 1 to 7 embryos depending on the availability each day, were loaded into $0.25 \mathrm{~mL}$ plastic straws. The straws were then transferred to an alcohol bath programmable freezer (ET-1, Fujihira, Tokyo, Japan) pre-cooled to $-6.5 \mathrm{C}$, and held for $8 \mathrm{~min}$.
Two minutes later, seeding was induced by touching the straws with a forceps pre-cooled in liquid nitrogen. Cooling was then continued to -35 $\mathrm{C}$ at $0.3 \mathrm{C} / \mathrm{min}$, and then the straws were plunged into liquid nitrogen. The straws were held for a period of $1 \mathrm{~d}$ to $2 \mathrm{wk}$ before thawing.

\section{Thawing and culture of embryos}

The straws were thawed by holding in air for 10 sec, and followed by warming in a water bath at 30 $\mathrm{C}$ for $20 \mathrm{sec}$. The straws were emptied directly into FM at $39 \mathrm{C}$ and the embryos were located. The embryos were then transferred into fresh FM followed by CR1-aa medium supplemented with $0.3 \%$ BSA for $10 \mathrm{~min}$ each at $39 \mathrm{C}$ in a $5 \% \mathrm{CO}_{2}$ incubator. The embryos were then washed twice in CR1-aa medium supplemented with 10\% FBS and cultured in the same medium for $48 \mathrm{~h}$ under $5 \%$ $\mathrm{CO}_{2}, 5 \% \mathrm{O}_{2}$, and $90 \% \mathrm{~N}_{2}$ at $39 \mathrm{C}$. Blastocysts with the original volume of the blastocoel $24 \mathrm{~h}$ after culture and with enlargement of the blastocoel $48 \mathrm{~h}$ after culture were considered to have survived [7].

\section{Statistical analysis}

Data on embryos surviving after freezing and thawing were analyzed using the Chi- square test and cell numbers were compared using the Student's t- test.

\section{Results}

Data in Table 1 present the cell numbers of Day 8 NT and IVF bovine blastocysts. In both NT and IVF groups, advanced-stage blastocysts contained significantly more ICM and TE cells than did earlystage embryos. While there was no significant difference in the cell number between NT and IVF blastocysts at the advanced-stage, there were significant differences in total and TE cell numbers of blastocysts at the early-stage.

The effect of developmental stage of blastocysts on the viability of embryos following freezing and thawing is shown in Table 2 . In both NT (89 vs $18 \%$ at $24 \mathrm{~h}, 86$ vs $14 \%$ at $48 \mathrm{~h}$ ) and IVF ( 87 vs $33 \%$ at 24 h, 87 vs $30 \%$ at 48 h) groups, advanced-stage blastocysts survived freezing significantly better than early-stage blastocysts. There was no significant difference in survival rate in the advanced ( 89 vs $87 \%$ at 24 h, 86 vs $87 \%$ at 48 h) or early-stage embryos (18 vs 33\% at 24 h, 14 vs $30 \%$ at 
Table 1. Cell numbers of NT and IVF bovine blastocysts before freezing

\begin{tabular}{llcccc}
\hline Group & Blastocyst stage & $\begin{array}{c}\text { No of embryos } \\
\text { examined }\end{array}$ & Total & Mean cell number $( \pm$ SD) & TEM \\
\hline NT & Advanced & 16 & $128 \pm 25^{\mathrm{a}}$ & $65 \pm 26^{\mathrm{a}}$ & $64 \pm 20^{\mathrm{a}}$ \\
& Early & 16 & $53 \pm 20^{\mathrm{b}}$ & $29 \pm 13^{\mathrm{b}}$ & $25 \pm 16^{\mathrm{b}}$ \\
IVF & Advanced & 13 & $128 \pm 29^{\mathrm{a}}$ & $53 \pm 21^{\mathrm{a}}$ & $74 \pm 21^{\mathrm{a}}$ \\
& Early & 16 & $75 \pm 22^{\mathrm{c}}$ & $30 \pm 12^{\mathrm{b}}$ & $45 \pm 18^{\mathrm{c}}$ \\
\hline
\end{tabular}

Values with different superscripts in a column differ significantly $(\mathrm{P}<0.01)$.

Table 2. Effect of developmental stage on the viability of NT and IVF bovine blastocysts after freezing and thawing

\begin{tabular}{|c|c|c|c|c|c|}
\hline \multirow[t]{2}{*}{ Group } & \multirow[t]{2}{*}{$\begin{array}{c}\text { Blastocyst stage } \\
\text { (replicates) }\end{array}$} & \multicolumn{2}{|c|}{ No. of embryos } & \multicolumn{2}{|c|}{$\begin{array}{c}\text { No. of embryos } \\
\text { surviving after (\%) }\end{array}$} \\
\hline & & thawed & cultured & $24 \mathrm{~h}$ & $48 \mathrm{~h}$ \\
\hline \multirow[t]{3}{*}{ NT } & Advanced (7) & 28 & 28 & $25(89)^{a}$ & $24(86)^{a}$ \\
\hline & Early (6) & 30 & 28 & $5(18)^{\mathrm{b}}$ & $4(14)^{\mathrm{b}}$ \\
\hline & Total & 58 & 56 & $30(53)^{c}$ & $28(50)^{c}$ \\
\hline \multirow[t]{3}{*}{ IVF } & Advanced (3) & 23 & 23 & $20(87)^{\mathrm{a}}$ & $20(87)^{\mathrm{a}}$ \\
\hline & Early (3) & 33 & 30 & $10(33)^{\mathrm{bc}}$ & $9(30)^{b c}$ \\
\hline & Total & 56 & 53 & $28(53)^{c}$ & $27(51)^{c}$ \\
\hline
\end{tabular}

Values with different superscripts in the same column differ significantly $(\mathrm{P}<0.001)$.

$48 \mathrm{~h}$ ) between NT and IVF embryos. The total number of blastocysts surviving cryopreservation in the NT and IVF groups was not significantly different (Table 2).

\section{Discussion}

The present study clearly demonstrated that advanced-stage NT blastocysts survived freezing better than early-stage blastocysts (Table 2). This observation was consistent with those for in IVF blastocysts $[8,9,11,12,20,21]$. To our knowledge, this is the first report comparing advanced- and early-stage NT blastocysts with respect to their survival after cryopreservation. In both the NT and IVF groups advanced-stage blastocysts survived freezing significantly better than early-stage embryos. While the reason(s) for better cryosurvival of advanced-stage embryos remains to be established, we speculate that in addition to the embryo quality, it might be related to the higher total cell number in these embryos. In the present study, early-stage IVF embryos survived freezing better (though not significantly) than early-stage NT blastocysts. While no significant differences were observed in total, ICM and TE cell numbers between NT and IVF advanced-stage blastocysts, IVF early-stage blastocysts had significantly higher total and TE cell numbers than the NT early-stage blastocysts. Slow freezing markedly reduced the number of TE cells (38 vs $27 \%$ ) compared to ICM cells in bovine IVF blastocysts [22]. Although we did not examine the cell numbers of freeze-thawed blastocysts, TE cell numbers of NT early-blastocysts might be too small to survive after freezing and thawing. Rapidly developing blastocysts have a higher cell number [23] and early developing blastocysts are more likely to survive freezing and establish pregnancies [17]. It is possible that in our study the advanced-stage embryos frozen on Day 8 might have developed from rapidly cleaving/ developing blastocysts. In view of the high cryosurvival rate and high total cell numbers observed in this study, and the small proportion of ploidy errors in large expanded bovine NT blastocysts [24], the large size expanded/ advanced-stage NT bovine blastocysts appear to be better quality blastocysts for selection of NT blastocysts in bovine.

Bovine embryos produced in vitro are characterized by their higher chilling sensitivity 
and lower freezability compared to their in vivo counterparts [25]. In the present study, however, the post freeze-thaw developmental potential of NT and IVF embryos of similar stages was not significantly different. This is consistent with our previous reports on cryopreservation of NT embryos $[6,7]$. These reports, along with the present study, suggest that the method of in vitro production (NT vs IVF) has no influence on freezability or chilling sensitivity of bovine blastocysts. Therefore, the in vitro culture conditions could be mainly responsible for the higher chilling sensitivity observed with embryos produced in vitro, as suggested earlier [26, 27]. This is supported by an earlier observation that culture of in vitro-produced bovine zygotes in ewe oviduct can dramatically increase their cryotolerance, to a level similar to that of embryos produced totally in vivo $[26,27]$.
The results of this study also support the hypothesis that an intact zona pellucida is not essential to for achieving good cryosurvival, as reported earlier [28]. However, further studies are required to examined the developmental potential of frozen-thawed nuclear-transferred blastocysts into calves.

\section{Acknowledgements}

This work was supported by grants from the Program of Promotion of Basic Research Activities for Innovative Biosciences (PROBRAIN), the Ministry of Culture, Sports, and Technology (14034259, 15039233, 16200030). DA was supported by Monbukagakushou Fellowship, Government of Japan.

\section{References}

1. Wilmut I, Schnieke AE, McWhir J, Kind AJ, Campbell KHS. Viable offspring derived from fetal and adult mammalian cells. Nature 1997; 385: 810813.

2. Tsunoda Y, Kato Y. Recent progress and problems in animal cloning. Differentiation 2002; 69: 158-161.

3. Renard JP, Zhou Q, Lebourhis D, Chavatte- Palmer P, Hue I, Heyman Y, Vignon X. Nuclear transfer technologies: between successes and doubts. Theriogenology 2002; 57: 203-222.

4. Han YM, Kang YK, Koo DB, Lee KK. Nuclear reprogramming of cloned embryos produced in vitro. Theriogenology 2003; 59: 33-44.

5. Niemann H, Wrenzycki C, Lucas-Hahn A, Brambrink T, Kues WA, Carnwath JW. Gene expression pattern in bovine in vitro produced and nuclear transfer derived embryos and their implications for early development. Cloning Stem Cells 2002; 4: 29-38.

6. Takano H, Kozai C, Shimizu S, Kato Y, Tsunoda Y. Cloning of bovine embryos by multiple nuclear transfer. Theriogenology 1997; 47: 1365-1373.

7. Nguyen BX, Sotomaru Y, Tani T, Kato Y, Tsunoda Y. Efficient cryopreservation of bovine blastocysts derived from nuclear transfer with somatic cell using partial dehydration and vitrification. Theriogenology 2000; 53: 1439-1448.

8. Han YM, Yamashina H, Koyama N, Lee KK, Fukui Y. Effects of quality and developmental stage on the survival of IVF derived bovine blastocysts cultured in vitro after freezing and thawing. Theriogenology
1994; 42: 645-654.

9. Carvalho RV, Del Campo MR, Palasz AT, Plante Y, Mapletoft RJ. Survival rates and sex ratio of bovine IVF embryos frozen at different developmental stages on day 7. Theriogenology 1996; 45: 489-498.

10. Saha S, Rajamahendran R, Boediono A, Sumantri C, Suzuki T. Viability of bovine blastocysts obtained after 7,8 or 9 days of culture in vitro following vitrification and one step rehydration. Theriogenology 1996; 46: 331-343.

11. Dinnyes A, Lonergan P, Fair T, Boland MP, Yang $\mathbf{X}$. Timing of the first cleavage post-insemination affects cryosurvival of in vitro produced bovine blastocysts. Mol Reprod Dev 1999; 53: 318-324.

12. Sommerfeld V, Niemann $\mathbf{H}$. Cryopreservation of bovine in vitro produced embryos using ethylene glycol in controlled freezing or vitrification. Cryobiology 1999; 38: 95-105.

13. Kato Y, Tani T, Sotomaru Y, Kurokawa K, Kato J, Doguchi H, Yasue H, Tsunoda Y. Eight calves cloned from somatic cells of single adult. Science 1998; 282: 2095-2098.

14. Yin XJ, Tani T, Yonemura I, Kawakami M, Miyamoto K, Hasegawa R, Kato Y, Tsunoda Y. Production of cloned pigs from adult somatic cells by chemically assisted removal of maternal chromosomes. Biol Reprod 2002; 67: 441-446.

15. Kato Y, Tani T, Tsunoda Y. Cloning of calves from various somatic cell types of male and female adult, newborn and fetal cows. J Reprod Fertil 2000; 120: 231-237. 
16. Brackett BG, Oliphant G. Capacitation of rabbit spermatozoa in vitro. Biol Reprod Dev 1975; 40: 5-11.

17. Hasler JF, Henderson WB, Hurtgen PJ, Jin ZQ, McCauley AD, Mower SA, Neely B, Shuey LS, Stokes JE, Trimmer SA. Production, freezing and transfer of bovine IVF embryos and subsequent calving results. Theriogenology 1995; 43: 141-152.

18. Thouas GA, Korfiatis NA, French AJ, Jones GM, Trounson AO. Simplified technique for differential staining of inner cell mass and trophectoderm cells of mouse and bovine blastocysts. Reproductive Biomedicine Online 2001; 3: 25-29.

19. Voelkel SA, Hu YX. Direct transfer of frozenthawed bovine embryos. Theriogenology 1992; 37: 2337.

20. Hasler JF, Hurtgen PJ, Jin ZQ, Stokes JE. Survival of IVF derived bovine embryos frozen in glycerol or ethylene glycol. Theriogenology 1997; 48: 563-579.

21. Paugh PA, Ankersmit AEL, McGowan LT, Tervit HR. Cryopreservation of in vitro produced bovine embryos: effects of protein type and concentration during freezing or of liposomes during culture on post thaw survival. Theriogenology 1998; 50: 495-506.

22. Kaidi S, Bernard S, Lambert P, Massip A, Dessy F, Donnay I. Effect of conventional controlled-rate freezing and vitrification on morphology and metabolism of bovine blastocysts produced in vitro.
Biol Reprod 2001; 65: 1127-1134.

23. Jiang HS, Wang WL, Lu KH, Gordon I, Polge C. Examination of cell numbers of blastocysts derived from IVM, IVF and IVC of bovine follicular oocytes. Theriogenology 1992; 37: 229.

24. Booth PJ, Viuff D, Tan S, Holm P, Greve T, Callesen H. Numerical chromosomal errors in Day 7 somatic nuclear transfer bovine blastocysts. Biol Reprod 2003; 68: 922-928.

25. Leibo SP, Loskutoff NM. Cryobiology of in vitro produced bovine embryos. Theriogenology 1993; 39: 81-94.

26. Rizos D, Lonergan P, Ward F, Duffy P, Boland MP. Consequences of bovine oocyte maturation, fertilization, or early embryo development in vitro versus in vivo: implications for blastocyst yield and blastocyst quality. Mol Reprod Dev 2002; 61: 234-248.

27. Enright BP, Lonergan $\mathbf{P}$, Dinnyes A, Fair T, Ward FA, Yang $X$, Boland MP. Culture of in vitro produced bovine zygotes in vitro vs in vivo: implications for early embryo development and quality. Theriogenology 2000; 54: 659-673.

28. Vajta G, Holm P, Greve T, Callesen H. Comparison of two manipulation methods to produce in vitro fertilized, biopsied and vitrified bovine embryos. Theriogenology 1997; 47: 501-509. 